\title{
ИСТОРИЯ СТАНОВЛЕНИЯ ЭЛЕКТРОКАРДИОГРАФИИ: А.Ф. САМОЙЛОВ И ЕГО СТАТЬЯ «ЭЛЕКТРОКАРДИОГРАММЫҢ
}

\section{THE HISTORY OF DEVELOPMENT OF ELECTROCARDIOGRAPHY: A.F. SAMOILOV AND HIS ARTICLE "ELECTROCARDIOGRAMS"}

\section{A. Ivanova}

Summary: The article is devoted to the scientific activity of the Russian scientist, physiologist Alexander Filippovich Samoilov (1867-1930) the founder of electrocardiography in Russia. In the article a short biography of the scientist is presented, his main scientific interests are described. Special attention is paid to Samoilov's scientific publication «Electrocardiograms» which was issued in the Russian medical periodical press - a newspaper «Russian Doctor» in 1908. This work of Samoilov obviously became the first article in Russian in the domestic periodical press devoted to a method of electrocardiography and the possibility of its use in scientific work and medical practice. In this work Samoilov noted the possibility of using electrocardiography in medical practice as well as the necessity for a thorough study of theoretical bases of electrocardiography for its further practical use.

Keywords: history of electrocardiography, Alexander Filippovich Samoilov, Einthoven's string galvanometer, electrocardiogram, medical practice.
Иванова Анна Николаевна

Н.с., ФГБУН Федеральный исследовательский центр «Коми научный чентр Уральского отделения Российской академии наук» (2. Сыктывкар) anna1486@mail.ru

Аннотация: Статья посвящена научной деятельности русского ученого, физиолога Александра Филипповича Самойлова (1867-1930) - основоположника отечественной электрокардиографии. В статье представлена краткая биография ученого, отмечены его основные научные интересы. Особое внимание уделено научной публикации А.Ф. Самойлова «Электрокардиограммы», которая вышла в 1908 г. в периодическом издании по медицине - газете «Русский врач». Данная работа ученого, очевидно, стала первой публикацией на русском языке в отечественном периодическом издании, посвященной методу электрокардиографии и возможностям его применения в научной работе и в медицинской практике. В своей статье А.Ф. Самойлов отметил как возможности использования метода электрокардиографии в медицинской практике, так и необходимость тщательного изучения теоретических основ данного метода для его дальнейшего практического применения.

Ключевые слова: история электрокардиографии, Александр Филиппович Самойлов, струнный гальванометр Эйнтховена, электрокардиограмма, медицинская практика.
$\mathrm{B}$ 1900-е гг. для продажи были представлены первые коммерческие модели нового прибора для электрофизиологических экспериментов - струнного гальванометра Эйнтховена, появление которого привело к тому, что в медицинской практике стали применять метод электрокардиографии. Разработка коммерческих моделей прибора сделала возможным приобретение технического новшества для разных организаций и учреждений, что вело к увеличению числа научных публикаций о струнном гальванометре Эйнтховена и методе электрокардиографии. О своем опыте работы с новым прибором представители профессиональных сообществ писали на страницах научных изданий [1, р. 939940], информируя тем самым своих современников о полученных научных результатах и привлекая внимание коллег к струнному гальванометру Эйнтховена. В России прибор Эйнтховена впервые появился в Казанском университете в физиологической лаборатории профессора Александра Филипповича Самойлова [2, с. 32] - основоположника отечественной электрокардиографии. В данной статье мы обратимся к публикации А.Ф. Самойлова, вышедшей в отечественном периодическом издании после появления струнного гальванометра Эйнтховена в лаборатории Казанского университета и знакомившей читателей с методом электрокардиографии.

В 1908 г. в газете «Русский врач» - «еженедельной медицинской газете, посвященной всем отраслям клинической медицины, общественной и частной гигиене и пр[очее]» [3, с. 559], Александр Филиппович Самойлов опубликовал статью «Электрокардиограммы», в которой сообщал о струнном гальванометре Эйнтховена и перспективах использования нового прибора для медицинских целей. Это была публикация выступления Самойлова на годичном заседании Московского терапевтического общества 30 января 1908 г., о чем говорится в сноске к заголовку статьи [4, с. 1089]. Два года спустя после выхода работы Самойлова, в 1910 г., Владимир Филиппович Зеленин - на тот момент младший врач І-ой Гренадерской артиллерийской бригады - в статье «Электрокардиограмма, ее значение для физиологии, общей патологии, фармакологии и клиники» отмечал «...отсутствие литературы на русском языке...», посвященной данной теме. Кроме статьи профессора Самойлова, «помещенной» В «Русском враче» двумя годами ранее, Зеленин упомянул в своей работе только вышедшую но уже в 1910 г. во «Врачебной газете» «...краткую критическую статью проф. Яновского...» и «...сообщения А.А. Юдина 
и С.С. Стериопуло...», опубликованные в том же 1910 г. в «Трудах первого съезда российских терапевтов» [5, с. 677]. Вышеуказанная работа Александра Филипповича Самойлова, очевидно, была первой и до 1910 г. единственной публикацией на русском языке, вышедшей в отечественном периодическом издании и посвященной струнному гальванометру Эйнтховена и электрокардиографии.

Александр Филиппович Самойлов (1867-1930) родился в Одессе. Начальное образование получил в одесской гимназии. Увлекался математикой. В 1884 г. поступил на естественно-историческое отделение физико-математического факультета Новороссийского университета. Но кроме математики Самойлова также интересовала физиология. Окончив два курса в Новороссийском университете, где на тот момент не было медицинского факультета, он поступил на медицинский факультет Дерптского (с 1893 г. в связи с переименованием города - Юрьевского, с 1919 г. - Тартуского [6, с. 511512]) университета [2, с. 13-14]. Обучение в университете велось на немецком языке [7, р. 1624]. Только с 1891 г. на медицинском факультете университета начали назначать профессоров, читающих курсы на русском языке [8, c. VIII]. Следует отметить, что большая часть научных работ А.Ф. Самойлова была написана на немецком языке [9, с. 615]. Его статьи выходили в международных научных периодических изданиях [2, с. 55].

В университете А.Ф. Самойлов занялся изучением физиологии, фармакологии, биохимии [2, с. 14]. В 1891 г. (по некоторым сведениям - в 1892 г. [10, с. 479-480]) защитил написанную на немецком языке диссертацию «О судьбе железа в животном организме» на степень доктора медицины [2, с. 14]. В 1892 г. Самойлова командировали в Тобольск на борьбу с эпидемией холеры, но практикующим врачом он работал недолгое время. Решив заняться научной работой, Александр Филиппович поступил в Институт экспериментальной медицины в Санкт-Петербурге, в лабораторию Ивана Петровича Павлова на должность ассистента. В 1894 г. Самойлов перешел в Московский университет в лабораторию Ивана Михайловича Сеченова в качестве сверхштатного лаборанта при кафедре физиологии [2, с. 23; 10, с. 480]. Позже Иван Петрович Павлов написал о переходе своего сотрудника в другую лабораторию следующее: «Я хорошо не помню, был ли у нас разговор и какой о мотивах его перехода, но думаю, что главной причиной этого был склад его головы. Каждый из нас идет на то, что отвечает этому складу. А складу соответствуют разные области науки или разные методы одной и той же науки» [11, с. 331]. О своей работе Павлов писал, что у него «... преобладали в известные периоды, или даже временами исключительно применялись вивисекции и физиологохирургические операции, а Иван Михайлович Сеченов работал почти всегда только с химическими методами и физическими инструментами. Александра Филипповича, очевидно, влекло к инструментальной, физической физиологии. И действительно, впоследствии, достигши профессорства, Александр Филиппович сосредоточил главнейшую свою работу в электро-физиологии и сделал в этом отделе очень многое» [11, с. 331]. В 1896 г. Самойлов стал приват-доцентом Московского университета, читал «необязательные курсы по электрофизиологии и физиологии органов чувств» [2, с. 23, 25]. С 1897 по 1903 гг. читал «часть обязательного курса физиологии» по поручению естественно-исторического отделения физико-математического и медицинского факультетов университета [10, с. 480]. 3 октября 1903 г. Александр Филиппович был избран профессором кафедры зоологии, сравнительной анатомии и физиологии физико-математического факультета Казанского университета. В 1921 г. стал профессором кафедры физиологии Ветеринарного института в Москве. С 1924 года руководил одновременно и физиологической лабораторией Казанского университета, и кафедрой физиологии физико-математического факультета Московского университета [2, с. 31, 39, 42]. Самойлов также занимался преподавательской работой, связанной с обучением врачей. Так, И.А. Ветохин (в 1911 г. он пришел в лабораторию к профессору Самойлову на должность сверхштатного ассистента [2, с. 34]) писал: «После Октябрьской революции А.Ф. [Александр Филиппович] читал в Казани ряд превосходно составленных специальных курсов для врачей по графическим методам исследования сердца с электрокардиографией и по внутренней секреции. Вместе с врачами эти курсы слушали и ряд профессоров - медиков и ветеринаров из казанских вузов» [9, с. 615]. В 1920 г. Самойлов ввел курс физиологии и электрокардиографии в Казанском институте усовершенствования врачей. По приглашению Клинического института в Казани и Биофизического института в Москве читал специальный курс по электрокардиографии для врачей. Деятельность Самойлова была связана с организацией и работой первых в нашей стране электрокардиографических кабинетов [2; с. 37, 132; 12, с. 53]. Начиная с 1890-х гг. он выезжал за границу - сначала в европейские страны, а в 1922 г. он впервые посетил США. Во время своих заграничных поездок Александр Филиппович принимал участие в работе международных научных конференций, читал лекции в университетах, госпиталях (на курсах усовершенствования врачей), работал в лабораториях у иностранных коллег [2, с. 45, 49-50; 12, с. 55-56].

Научные интересы Самойлова были разнообразны. Он проводил исследования в области биохимии, фармакологии. Самойлова также интересовала физиология органов чувств. Но основная часть его научных исследований была связана с нервно-мышечной физиологией [9, с. 614; 13, с. 334, 344]. Научные работы Самойлова в области электрофизиологии получили признание отечественных и иностранных коллег еще при жизни ученого 
[2, с. 104], «роль Самойлова в электрофизиологии была огромна» [14, с. 344]. Его исследования легли в основу теоретической и клинической электрокардиографии [2, с. $107 ; 13$, с. 50]. А.Ф. Самойлов опубликовал свыше 20 работ по физиологии сердца и электрокардиографии [14, с. 16]. В 1909 г. была впервые издана монография по электрокардиографии, которая была написана Самойловым на немецком языке. В 2017 г. вышло русскоязычное издание данной книги [7, р. 1624; 12, с. 52-53].

К исследованиям в области электрофизиологии Александр Филиппович Самойлов приступил после переезда в Москву в лабораторию Сеченова. Там он начал работать с капиллярным электрометром [2, с. 24] - прибором для изучения электрических явлений в мышцах и нервах, появившимся ранее более чувствительного струнного гальванометра Эйнтховена. Самойлов занимался усовершенствованием прибора, довел «...технику фоторегистрации капиллярного электрометра до исключительной отчетливости и изящества» [13, с. 335], ввел новый метод для фотографирования показаний капиллярного электрометра, что «...позволило на одном снимке получать и сравнивать несколько кривых» $[13$, с. 52].

В 1904 г. А.Ф. Самойлов посетил VI Международный конгресс по физиологии в Брюсселе (Бельгия) и впервые встретился с Виллемом Эйнтховеном, который жил и работал в Лейдене (Голландия). Александр Филиппович писал: «Я встретился впервые с Эйнтховеном за несколько дней до открытия физиологического конгресса в Брюсселе в 1904 г. Я написал ему из Парижа, где я был в то время, и затем я остановился в Лейдене, чтобы навестить его. Я одновременно увидел Эйнтховена и его новый инструмент, струнный гальванометр...» [15, р. 546].

Выступление Эйнтховена на закрытии конгресса было посвящено работе двух приборов для электрофизиологических исследований и сравнению результатов, полученных при помощи капиллярного электрометра и гальванометра [16, р. 33]. Ученый также пригласил своих коллег по окончании конгресса посетить Лейден, где находился разработанный им струнный гальванометр [17, p. 270-271].

Вероятно, после посещения физиологического конгресса в Брюсселе А.Ф. Самойлов решил приобрести струнный гальванометр Эйнтховена для физиологической лаборатории физико-математического факультета Казанского университета. В монографии Н.А. Григорян «Александр Филиппович Самойлов» приведены сведения о том, что в 1906 г. Самойлов ходатайствовал о выделении физиологическому кабинету 425 руб. для приобретения струнного гальванометра. В результате было принято решение ассигновать на покупку прибора из средств Казанского университета 300 руб. в 1906 г. и отложить до 1907 г. выдачу оставшейся части суммы [2, с. 32]. При этом в монографии не указано, какая именно модель прибора была закуплена для университета. Как известно, изготовлением коммерческих моделей струнного гальванометра Эйнтховена на момент приобретения прибора для Казанского университета занимались несколько производителей научного оборудования: Макс Эдельман в Германии, Кембриджская инструментальная компания в Англии [1, р. 939].

В статье, посвященной жизни и научной деятельности профессора Самойлова, И.А. Ветохин упоминал о том, что «...очень скоро после изобретения Эйнтховена...» физиологическая лаборатория Александра Филипповича «...обогатилась установкой струнного гальванометра (модель Макса Эдельмана)» [14, с. 14].

Между тем, по имеющимся сведениям, для Казанского университета во втором полугодии 1908 г. была куплена и коммерческая модель струнного гальванометра Эйнтховена, разработанная Кембриджской инструментальной компанией [18, р. 75].

В дальнейшем физиологическая лаборатория Казанского университета пополнялась новым оборудованием [2, с. 32-33]. К примеру, в своей статье 1910 г. А.Ф. Самойлов указал, что в лаборатории в наличии было два струнных гальванометра конструкции Эдельмана: большой и малый. Причем малую модель прибора ученый использовал на лекциях с демонстрационной целью [19, S. 484].

Приведенные выше данные позволяют сделать предположение, что в Казанском университете в 1900-е гг. могло быть уже несколько моделей струнных гальванометров Эйнтховена разных изготовителей. Но дата появления первого струнного гальванометра Эйнтховена в физиологической лаборатории Казанского университета все же требует уточнений.

В своей публикации «Электрокардиограммы» в газете «Русский врач» 1908 г. Александр Филиппович Самойлов сообщал о появлении нового прибора в физиологической лаборатории следующее: «Струнный гальванометр был приобретен для лаборатории не в целях исследования больных. Электрокардиограмму нормального человеческого сердца я записывал только для того, чтобы проверить качество инструмента в отношении предъявленной к нему совершенно определенной и сравнительно трудной задачи» [4, с. 1093]. Ученый отмечал, что «... вопросы, которые она [электрофизиология] себе ставит, имеют в настоящее время совершенно определенный, реальный характер. Одним из таких вопросов является исследование электрических токов сердца и выработка способов графической записи их в виде кривой» [4, с. 1089]. В публикации не встречается именно термин «электрокардиография», метод был обозначен как «ме- 
тод электрокардиограмм», «метод записей электрических токов сердца».

В статье А.Ф. Самойлов привел характеристики, которыми должен обладать инструмент для записи «токов сердца» и в «кратких чертах» описал принцип струнного гальванометра Эйнтховена, «получившего в короткое время большое распространение и разнообразное применение» [4, с. 1090]. Также в публикации были показаны «кривые сердечных токов действия» здорового человека, дано описание «частей электрокардиограммы», представленных ранее Эйнтховеном [4, с. 1091]. А.Ф. Самойлов рассмотрел «сочетанную электрокардиограмму 2-х сердец, принадлежащих 2-м лицам и включенных в одну цепь [с гальванометром]» [4, с. 1092]. Александр Филиппович отмечал, что прибор Эйнтховена позволил получить «...такую картину, на основании которой мы сразу можем сказать: здесь бились 2 сердца», «...можем сделать обоснованное предположение...» о расположении обоих сердец или тел, заключающих их, относительно друг друга [4, с. 1092].

В статье сообщалось, что благодаря просьбе своего коллеги, врача, профессора Казанского университета А.Н. Казем-Бека, который в 1904-1916 гг. возглавлял кафедру факультетской терапии [20, с. 23], Самойлову представился случай использовать новый прибор для обследования больного. Александр Филиппович писал: «... когда техника пользования инструментом была окончательно налажена, я, по просьбе проф. А.Н. Казем-Бека, согласился записать кривую сердечных токов одной больной женщины, присланной из клиники в лабораторию. Я не знал характера ее сердечного заболевания и, конечно, не исследовал ее, потому что со времени школьной скамьи практической медициной не занимался. Я отвел токи ее сердца через обе руки к гальванометру и экспонировал электрокардиограмму. Через минуту, проявляя кривую в темной комнате, я заметил сильнейшее отклонение кривой от нормального вида. Было ясно, что часть электрокардиограммы, соответствующая предсердию, значительно выше и продолжительнее, чем в электрокардиограмме нормального сердца; очевидно, предсердие работало с бо́льшим напряжением, чем обыкновенно у здорового человека. Оказалось, что обычными способами у этой больной было найдено сужение левого атриовентрикулярного отверстия. Итак, мой диагноз, по существу дела совпадавший с диагнозом клинициста, но основанный на данных электрокардиограммы, определял характер забо- левания с иной стороны, со стороны силы деятельности предсердия» [4, с. 1093]. А.Ф. Самойлов полагал, что можно было «...жжидать плодотворного применения гальванометрических исследований в области патологии сердца» и что «...в клинике найдутся люди с физической и физиологической подготовкой, которые при добром желании и надлежащем руководстве овладеют методом записей электрических токов сердца» [4, с. 1094]. Но при этом, по мнению Александра Филипповича, открывающимися для клинической медицины возможностями следовало правильно распорядиться. Ученый писал: «Клиника поставлена, как бы в положение человека, который должен получить большое богатство и стоит перед трудной задачей справиться с этим богатством, использовать его наиболее целесообразно». К тому же, для внедрения нового диагностического метода в медицинскую практику требовалось изучение теоретических основ данного метода. Самойлов отмечал: «Вопрос о сердечных электрических токах в его применении к патологическим случаям не находится еще в состоянии широкого практического пользования им. Вопрос этот останется еще, очевидно, на долгое время предметом исключительного научного исследования, и при том исследования тщательного и осторожного; осторожность здесь требуется особенно в виду сложности и тонкости метода исследования, а чем метод сложнее, тем больше, конечно, оснований для погрешностей» [4, с. 1094].

Таким образом, в 1900-е гг. (период появления первых коммерческих моделей струнного гальванометра Эйнтховена) научные публикации на национальных языках, содержавшие сведения о принципах работы нового прибора для регистрации электрических явлений в сердце и возможностях его использования в научной работе и медицинской практике, способствовали распространению сведений о методе электрокардиографии в разных странах мира. Вышедшая в 1908 г. в медицинской периодической печати научная работа Александра Филипповича Самойлова «Электрокардиограммы» стала, очевидно, первой публикацией на русском языке в отечественном периодическом издании, посвященной струнному гальванометру Эйнтховена и методу электрокардиографии. В своей статье А.Ф. Самойлов показал как возможности использования метода графической регистрации электрических токов сердца в медицинской практике, так и указал на необходимость тщательного изучения теоретических основ данного метода для его дальнейшего практического применения.

ЛИТЕРАТУРА

1. Fye W.B. A history of the origin, evolution, and impact of electrocardiography // The American Journal of Cardiology. 1994. Vol. 73(13). P. 937-949.

2. Григорян Н.А. Александр Филиппович Самойлов. М.: Изд-во Академии наук СССР, 1963. 203 с. 
3. Русский врач // Энциклопедический словарь Брокгауза и Ефрона. Доп. т. Ila. СПб., 1907. С. 559. URL: https://dlib.rsl.ru/viewer/01003924173\#?page=1 (дата обращения: 14.05.2020).

4. Самойлов А.Ф. Электрокардиограммы // Русский врач. 1908. № 33. С. 1089-1094.

5. Зеленин В.Ф. Электрокардиограмма, ее значение для физиологии, общей патологии, фармакологии и клиники // Военно-медицинский журнал. 1910. Т. CCXXVIII. C. 677-688.

6. Алликметс Л.Х., Калнин В.В. Тартуский государственный университет // Большая медицинская энциклопедия. Т. 24 / Гл. ред. Б.В. Петровский. 3-е изд. М.: Советская энциклопедия, 1985. С. 511-513.

7. Krikler D.M. The search of Samojloff: a Russian physiologist in times of change // British Medical Journal. 1987. Vol. 295(6613) P. 1624-1627. URL: https://www. ncbi.nlm.nih.gov/pmc/articles/PMC1257495/ (дата обращения: 24.06.2020).

8. Чиж Очерк истории медицинского факультета Императорского Юрьевского (бывшего Дерптского) университета // Биографический словарь профессоров и преподавателей Императорского Юрьевского, бывшего Дерптского, университета за сто лет его существования (1802-1902). Т. 2 / Под ред. Г.В. Левицкого. Юрьев: типография К. Маттисена, 1903. С. I-XVI. URL: https://dspace.ut.ee/handle/10062/17434 (дата обращения: 03.07.2020).

9. Ветохин И.А. А.Ф. Самойлов // Русский физиологический журнал имени И.М. Сеченова. 1930. Т. XIII. № 6. С. 613-616.

10. Самойлов Александр Филиппович // Биографический словарь профессоров и преподавателей Императорского Казанского университета: за сто лет (1804-1904). В 2 ч. Ч. І: кафедра православного богословия, факультеты историко-филологический (с разрядом восточной словесности и лектурами) и физико-математический / Под ред. Н.П. Загоскина. Казань: типо-литография Императорского университета, 1904. С. 479-481. URL: https://dlib.rsl.ru/ viewer/01003976176\#?page=2 (дата обращения: 03.07.2020).

11. Павлов И.П. Памяти Александра Филипповича Самойлова // Казанский медицинский журнал. 1931. № 4-5. С. 331-332.

12. Зефиров А.Л., Звёздочкина Н.В. Александр Филиппович Самойлов - основоположник электрофизиологических исследований Казанской физиологической школы // Журнал фундаментальной медицины и биологии. 2017. № 2. С. 50-57.

13. Воронцов Д.С. Научно-исследовательская деятельность А.Ф. Самойлова // Казанский медицинский журнал. 1931. № 4-5. С. 334-344.

14. Ветохин И.А. Александр Филиппович Самойлов (краткий очерк жизни и научной деятельности) // Вопросы физиологии человека и животных / Под ред. Г.С. Юньева. Минск: Изд-во Белгосуниверситета им. В.И. Ленина, 1960. Вып. 1. С. 5-22.

15. Samojloff A. Reminiscences of the late Professor Willem Einthoven // American Heart Journal. 1930. Vol. 5(5). P. 545-548.

16. Slosse A. Compte rendu du Vle Congrès international de Physiologie ( 30 août -3 septembre). Procès-verbaux des séances du Vle Congrès // Archives internationales de physiologie. 1904-1905. Vol. II. P. 19-35. URL: https://archive.org/stream/archivesinterna06unkngoog\#раge/n6 (дата обращения: 05.09.2020).

17. Franklin K.J. A short history of the International Congresses of physiologists // Annales of Science. 1938. Vol. 3(3). P. 241-335.

18. Burnett J. The origins of the electrocardiograph as a clinical instrument // Medical history, supplement. 1985. № 5. P. 53-76. URL: https://www.ncbi.nlm.nih.gov/ pmc/articles/PMC2557409/ (дата обращения: 17.06.2020).

19. Samojloff A. Praktische Notizen zur Handhabung des Saitengalvanometers und zur photographischen registration seiner Ausschläge // Archiv für Anatomie und Physiologie. Physiologische Abteilung. 1910. S. 477-514. URL: https://www.biodiversitylibrary.org/item/103249\#page/9/mоde/1uр (дата обращения: 19.06.2020).

20. Казем-Бек Алексей Николаевич // Большая медицинская энциклопедия. Т. 10 / Гл. ред. Б.В. Петровский. 3-е изд. М.: Советская энциклопедия, 1979. С. 23.

(с) Иванова Анна Николаевна (anna1486@mail.ru).

Журнал «Современная наука: актуальные проблемы теории и практики» 